\title{
Regulation of Cbfa1 Expression by Total Flavonoids of Herba Epimedii
}

\author{
GUOFENG QIAN, XIUZHen ZHANG, LIXIA LU*, XINJIANG WU**, SHUMEI LI AND JiAN MENG \\ Department of Endocrinology, Tongji Hospital of Tongji University, 389 Xincun Road, Shanghai 200065, P.R. China \\ *Department of Biochemistry, School of Medicine, Tongji University, 1239 Siping Road, Shanghai 200092, P.R. China \\ **Institute of Indoor and Environmental Toxicology, Justus-Liebig-University of Giessen, Aulweg 123, D-35385 Giessen, Germany
}

\begin{abstract}
Core binding factor $\alpha 1$ (Cbfa1) is a member of the runt family of transcription factors, which appears to play a pivotal role in regulating the differentiation of osteoblastic precursors and the activity of mature osteoblasts. Total flavonoids of Herba epimedii (HEF) is a recognized bone anabolic agent, but there is lack of reports on the modulation of Cbfa1 expression by HEF. Here we investigated the effect of HEF on Cbfa1 expression in the bone of ovariectomized (OVX) rats. HEF could increase the expression of Cbfal mRNA in the bone of ovariectomized rats in a dose-dependent manner. Furthermore, the high dose HEF $(160 \mathrm{mg} / \mathrm{kg})$ administered for 12 weeks in vivo stimulated osteocalcin expression. These findings suggest that Cbfal is required for mediating the anabolic effects of HEF.
\end{abstract}

Key words: Total flavonoids of Herba epimedii, Core binding factor $\alpha 1$, Osteoporosis

(Endocrine Journal 53: 87-94, 2006)

HERBA epimedii (which also goes by the names Yin Yang Huo and Horny Goat Weed) is a traditional botanical medicine used in China, Japan and Korea. As an herb, it has a history of traditional use for disorders of the kidneys, joints, liver, back and knees. Pharmacological studies have shown its potential activity against osteoporosis [1-3], and its main constituent is total flavonoids of Herba epimedii (HEF). At present, HEF anabolic effects on bone have been verified in many studies. In experimental animals with osteoporosis, administration of HEF increases bone mass by stimulating de novo bone formation [1]. In vitro, this increase in bone mass is associated with an increased activity of existing osteoblasts and an increased differentiation of osteoblasts [2]. But the underlying molecular mechanisms accounting for these osteoblastic effects of HEF remain unclear.

The recent discovery of Cbfa1 (Runx2, OSF2, AML3,

Received: January 6, 2005

Accepted: October 24, 2005

Correspondence to: Dr. Xiuzhen ZHANG, Department of Endocrinology, Tongji Hospital of Tongji University, 389 Xincun Road, Shanghai 200065, P.R. China
Pebp2 $\alpha \mathrm{A})$ as a master regulatory gene in the osteoblast is of great importance. Cbfa1 is a member of the runt family of transcription factors, whose expression is required for the differentiation of osteoblastic precursors and modulating the activity of mature osteoblasts [4]. Targeted deletion of the Cbfal gene resulted in a complete lack of skeleton and absence of functional osteoblasts due to maturational arrest [5]. Specific expression of a dominant-negative Cbfal in mature osteoblasts resulted in severe reduction in bone formation and bone mass due to a decrease in osteoblast activity [6]. Additionally, several in vitro studies have demonstrated that $\mathrm{Cbfa} 1$ is a major regulator of the osteoblast phenotype and is necessary for osteoblastspecific expression of genes such as osteocalcin, type I collagen, osteopontin, and bone sialoprotein [4-6].

Based on in vitro data and the phenotypes of mice with altered Cbfa1 expression, it seems that the expression and regulation of Cbfal activity in osteoblastic lineage cells might be important in determining bone formation induced by anabolic agents. In this context, it is reasonable to speculate that HEF anabolic effect on bone may be involved in the control of a master regulatory gene(s) whose expression and activity governs 
osteoblast function.

In the present study, our data demonstrated that the expression of Cbfal mRNA was enhanced by HEF in the bone of ovariectomized rats in a dose-dependent manner.

\section{Materials and Methods}

\section{Materials}

HEF is composed of icariin and icariside. Icariin is the main active constituent. Its molecular weight is 676.65 and its structural formula is shown in Fig. 1. HEF and icariin were purchased from Pharmaceutical Industry Research Institute, Shanghai, China. They were isolated from dried aerial parts of Herba epimedii by the method described previously [7]. Dried aerial parts of Epimedii herba was extracted 3 times with ethanol, yielding an ethanol extract upon removal of the solvent in vacuo. The ethanol extract was then suspended in water and partitioned successively with n-hexane, $\mathrm{CHCl}_{3}$ and $\mathrm{n}-\mathrm{BuOH}$ to obtain different fractions. Different fractions were combined and dis-

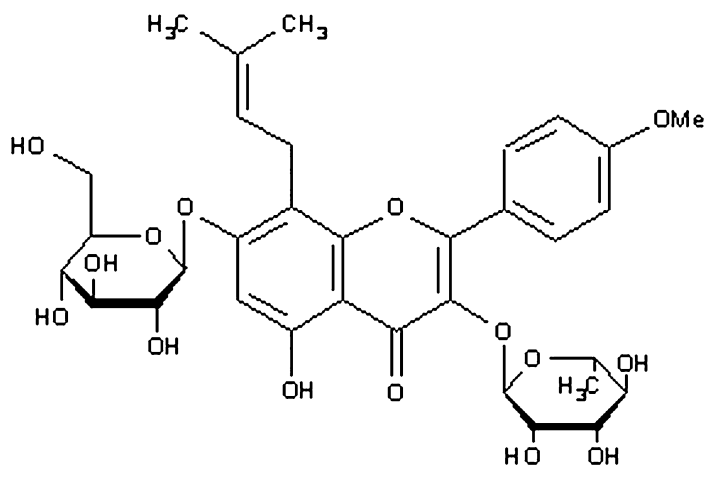

(A)

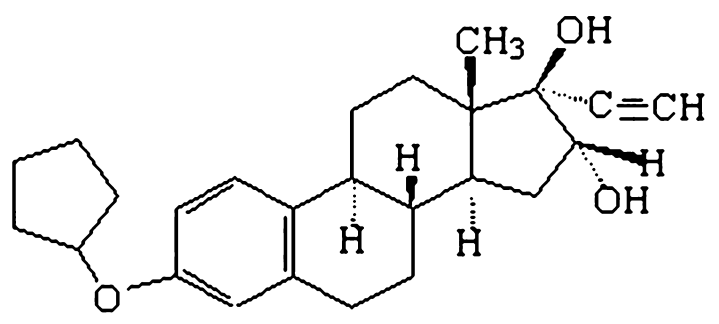

(B)

Fig. 1. Structures of icariin (A) and nilestriol (B). tilled. The crude extract was then purified twice with methanol. The final extract contained $63.41 \%$ total flavonoids (27.99\% icariin) as determined by HPLC. For in vitro experiments, the $\mathrm{n}-\mathrm{BuOH}$ fraction was spread out using silica gel column chromatography to isolate icariin, which was purified through repeated recrystallization from $\mathrm{MeOH}$. This resulted in an amorphous yellow powder that consisted of $91 \%$ icariin as verified by HPLC.

Nilestriol, a derivative of estriol, was purchased from Hualian Pharmaceutical Co., Ltd., Shanghai, China. Generally, it is used for hormone replacement therapy in perimenopausal women. Its molecular weight is 380.53 , and its structural formula is also shown in Fig. 1.

\section{Experimental design}

\section{In vitro experiments}

Rat primary osteoblasts were isolated from newborn pups ( $<24 \mathrm{~h}$ old). Calvariae were removed and washed with PBS. The fibrous tissue surrounding the bone was gently scraped off, the calvariae were divided in two halves, and sutures were removed. The trimmed calvariae were treated with $0.25 \%$ trypsin (Amresco, USA) solution for $10 \mathrm{~min}$ at $37^{\circ} \mathrm{C}$. Then calvariae were subjected to two 60 -minute sequential collagenase $(0.1 \%)$ (Sigma, USA) digestions in an oscillating $37^{\circ} \mathrm{C}$ water bath. Digestions were neutralized with $\alpha$-MEM (Gibco, USA), pooled, and filtered through a sterile polypropylene mesh of 200-297 $\mu$. The filtrate was centrifuged for $10 \mathrm{~min}$ at $1000 \mathrm{rpm}$, the supernatant was removed, and cells were resuspended in 3-5 $\mathrm{ml} \alpha$-MEM containing 10\% fetal calf serum (FCS) (Sino-American Biotechnology Co, China). Cells were then diluted to $2 \times 10^{4}$ per $\mathrm{ml}$ and plated onto culture dishes $(2 \mathrm{ml}$ per culture dish). The next morning the medium was exchanged. Thereafter, cells were grown with a regular medium exchange every third day.

For the set of the cells treated with icariin, the cells were cultured in the presence of $1 \mathrm{ng}, 10 \mathrm{ng}$ or $100 \mathrm{ng} /$ $\mathrm{ml}$ of icariin. Icariin treatment was conducted for $48 \mathrm{~h}$ using the cells at $80 \%$ confluency.

\section{In vivo experiments}

Three-month-old female SD rats were obtained from the Central Animal Department of Fudan University, Shanghai, China. The animals were housed in a controlled environment animal facility at $24 \sim 28^{\circ} \mathrm{C}$ with a 
12-h light/dark cycle. During the experiment, the animals were given free access to food and distilled water. The Institutional Animal Care and Use Committee (IACUC) approved all animal procedures.

After 7 days of acclimation, the rats were divided into two groups: bilateral ovariectomy or sham operation. A week after surgery, the rats were divided into six groups $(n=9)$ : $(1)$ sham operated + vehicle $(0.9 \%$ sodium chloride solution, Shanghai Worldbest Treeful Pharmaceuticals Co., Ltd., China); (2) ovariectomized $(\mathrm{OVX})+$ ehicle; (3) OVX + nilestriol $(0.1 \mathrm{mg} / \mathrm{kg}$ per week, gavage); (4) OVX + Low dose-HEF (L-HEF) (40 mg/kg per day, gavage); (5) OVX + Middle doseHEF (M-HEF) (80 mg/kg per day, gavage); (6) OVX + High dose-HEF (H-HEF) (160 mg/kg per day, gavage). The rats received drug treatment for 12 weeks. Body weights were determined every week. After treatments, blood samples were collected by heart puncture, and the serum was centrifuged $(3,000 \mathrm{rpm}, 20 \mathrm{~min}$ at $4^{\circ} \mathrm{C}$ ), aliquoted, and stored at $-20^{\circ} \mathrm{C}$ until measurements were made. Skulls were dissected and stored in liquid nitrogen until measurements were made.

\section{Measurement of bone mineral density (BMD)}

BMD was measured in total body by dual-energy $\mathrm{x}$ ray absorptiometry (DEXA) (Lunar, USA), which was calculated as quotient of the projected bone area $\left(\mathrm{cm}^{2}\right)$ and bone mineral content $(\mathrm{g})$. The machine was calibrated daily with a phantom provided by the manufacturer. The coefficient of variation (CV) of DEXA was less than $1.0 \%$.

\section{Serum osteocalcin $(B G P)$ and estradiol $\left(E_{2}\right)$}

Serum BGP and $\mathrm{E}_{2}$ were measured by a radioimmunological kit (Chemclin Biotech Co. Ltd., Beijing, China).

Reverse transcription-polymerase chain reaction ( $R T$ PCR)

Total RNA was harvested from the cells with Trizol reagent (Gibco, USA) and isolated according to the manufacturer's instructions. First-strand cDNA was synthesized from total RNA by using Oligo(dT) primer and M-MLV reverse transcriptase (Promega, USA). Samples were incubated at $42^{\circ} \mathrm{C}$ for $1 \mathrm{~h}$. Subsequently, PCR was performed with Taq DNA Polymerase
(Promega, USA); initial denaturation occurred at $94^{\circ} \mathrm{C}$ for $5 \mathrm{~min}$, with final extension at $72^{\circ} \mathrm{C}$ for $7 \mathrm{~min}$ for each set of primers. The amplification was carried out using the following specific oligonucleotides:

Bone morphogenetic protein 2 (BMP-2):

5'-GGACTGCGGTCTCCTAAA-3' and 5'-GCTCA AACTCAACTCCGAC-3'

GAPDH:

5'-ACCACAGTCCATGCCATCAC-3' and 5'-ATG TCGTTGTCCCACCACCT-3'

GAPDH served as control. Conditions set for the investigated genes were: $94^{\circ} \mathrm{C} 30 \mathrm{sec}, 57^{\circ} \mathrm{C} 45 \mathrm{sec}$, $72^{\circ} \mathrm{C} 1 \mathrm{~min}\left(32\right.$ cycle) for BMP-2; $94^{\circ} \mathrm{C} 30 \mathrm{sec}, 56^{\circ} \mathrm{C}$ $45 \mathrm{sec}, 72^{\circ} \mathrm{C} 1 \mathrm{~min}$ (32 cycle) for GAPDH.The PCR products were analyzed by electrophoresis on $2 \%$ agarose gels, stained with ethidium bromide. Finally, the gels were subjected to imaging and densitometric scanning of the resulting bands under UV light.

\section{Real-time quantitative RT-PCR}

\section{$R N A$ isolation and reverse transcription}

The skull was dissected from each rat and stored in liquid nitrogen until used. Total RNA was isolated from the skull using RNAgents ${ }^{\circledR}$ total RNA isolation system (Promega, USA). Five $\mu \mathrm{g}$ of total RNA was reverse-transcribed by incubation with $1 \mu \mathrm{l}$ of $5 \mu \mathrm{M}$ oligo (dT) primer $65^{\circ} \mathrm{C}$ for $5 \mathrm{~min}$; afterwards $2 \mu \mathrm{l}$ of $10 \mathrm{mM}$ dNTPs, $1 \mu \mathrm{l}$ of $0.1 \mathrm{M}$ DTT (Invitrogen, USA), $4 \mu \mathrm{l}$ of reverse transcriptase buffer (Promega, USA), and 50 units of M-MLV reverse transcriptase (Promega, USA) were added in a total volume of $20 \mu \mathrm{l}$. The mixture was incubated at $42^{\circ} \mathrm{C}$ for $1 \mathrm{hr}$.

\section{Determination of optimum primer and probe}

Taqman PCR assays were performed on a Corbett Rotor-Gene 3000 real-time PCR system (Corbett Research, Australia). First optimum primer concentrations for different expressed sequenced tags (ESTs), which combined same concentrations of both forward and reverse primers with a constant probe concentration, were determined. Then optimum probe concentrations were determined.

Determination of amplification efficiency for target and reference

The optimal concentrations for primer and probe were used in reactions for determination of amplification efficiency. Duplicates of cDNA templates were 
used for every run. To determine amplification efficiency of target and reference, a calibration curve was used. For this purpose, a stock solution of cDNA from which we prepared serial dilution was prepared. A calibration curve with $125,25,5,1,0.2 \mathrm{ng}$ of cDNA was created for ESTs. Overall efficiencies (E) of PCR were calculated from the slopes of the standard curves according to the $\mathrm{E}=10^{[-1 / \text { slope }]}$ for serial dilution in steps of $10[\log (10)$ scale $] . E=2$ reflects a doubling of DNA in each PCR cycle over all dilution steps. Two regression lines were used to compare the significance of difference between two slopes of curve regression for target and reference, respectively. If there was no significant difference, relative quantification of $\mathrm{Cbfa} 1$ mRNA expression was calculated by $\Delta \Delta \mathrm{Ct}$; otherwise, it was calculated by Rasmussen $[8,9]$.

\section{Real-time quantitative RT-PCR}

Due to valuable samples and more fragments requiring validation, the reaction setup was scaled down appropriately to $25 \mu \mathrm{l}$. The thermal cycling conditions were at $95^{\circ} \mathrm{C}$ for $3 \mathrm{~min}$, followed by 45 cycles of at $94^{\circ} \mathrm{C}$ for $5 \mathrm{sec}$ and at $65^{\circ} \mathrm{C}$ for $40 \mathrm{sec}$. Primer and Taqman probe sets were designed from sequences in the Genebank database using Primer Express 2.0 software. The sequences are listed in Table 1 .

\section{Statistical analysis}

Data were presented as the mean $\pm \mathrm{SEM}$. For statistical evaluation, data were compared using the ANOVA test and $P<0.05$ was considered significant.

\section{Results}

Body weight was not influenced by HEF

Before treatments, body weights of six groups of rats did not differ (data not shown). After experiments, body weight of rats in OVX group was higher than that in sham-operated group $(P<0.01)$. Intake of HEF for 12 weeks did not affect the body weight $(P>0.05)$ (Fig. 2).

\section{Increase of BMD by HEF}

Marked bone loss occurred in the rats of OVX group, and this loss was prevented by treatment with HEF. Administration of nilestriol also prevented the bone loss in OVX rats.

Ovariectomy led to significant decrease of BMD of

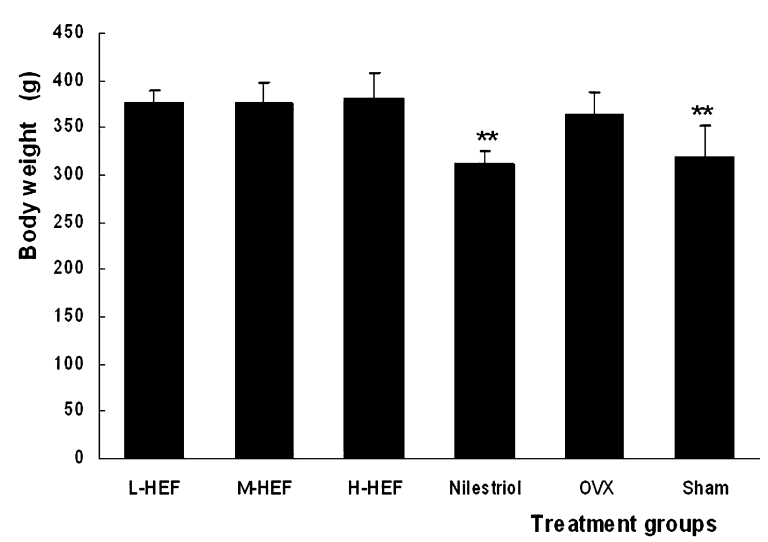

Fig. 2. Final body weight in sham-operated rats (Sham); ovariectomized (OVX) rats treated with vehicle; OVX rats treated with L-HEF or M-HEF or H-HEF; OVX rats treated with nilestriol. Data are means \pm SEM of nine rats. Different from OVX group: $* P<0.05$, $* * P<0.01$ by ANOVA. HEF, total flavonoids of Herba epimedii; OVX, ovariectomized; L-HEF, Low dose HEF; M-HEF, Middle dose HEF; H-HEF, High dose HEF.

Table 1. Primer and probe sequence (forward primer, reverse primer, Taqman probe)

\begin{tabular}{llll}
\hline \multirow{2}{*}{ Name } & $\begin{array}{c}\text { Gen Bank } \\
\text { accession number }\end{array}$ & \multicolumn{1}{c}{ Sequence } \\
& AF053950 & Forward primer & 5'-TGCTTCATTCGCCTCACAAA-3' \\
& & Reverse primer & 5'-TGCTGTCCTCCTGGAGAAAGTT-3' \\
& & Probe & 5'-AACCACAGAACCACAAGTGCGGTGC-3' \\
GAPDH & \multirow{2}{*}{ U75401 } & Forward primer & 5'-GAACATCATCCCTGCATCCA-3' \\
& & Reverse primer & 5'-CCAGTGAGCTTCCCGTTCA-3' \\
& & Probe & 5'-CTTGCCCACAGCCTTGGCAGC-3' \\
\hline
\end{tabular}


Table 2. Effect of HEF on bone mineral density (BMD) in ovariectomized rats

\begin{tabular}{lc}
\hline Group & Bone mineral density $\left(\mathrm{g} / \mathrm{cm}^{2}\right)$ \\
\hline L-HEF & $0.2920 \pm 0.006874$ \\
M-HEF & $0.2931 \pm 0.006294$ \\
H-HEF & $0.2975 \pm 0.006626^{*}$ \\
Nilestriol & $0.2964 \pm 0.006464^{*}$ \\
OVX & $0.2918 \pm 0.002438$ \\
Sham & $0.3030 \pm 0.012294^{*}$ \\
\hline
\end{tabular}

Data are means \pm SEM of nine rats.

After 12 weeks, BMD was measured in total body by dual-energy $\mathrm{x}$-ray absorptiometry, which was calculated as quotient of the projected bone area $\left(\mathrm{cm}^{2}\right)$ and bone mineral content $(\mathrm{g})$.

Different from OVX group: $* P<0.05$ by ANOVA

HEF, total flavonoids of Herba epimedii; OVX, ovariectomized; L-HEF, Low dose HEF; M-HEF, Middle dose HEF; H-HEF, High dose HEF

total body compared to the sham-operated group $(P<0.05)$. However, HEF administration increased BMD of total body in a dose-dependent manner. The statistical significant increase of BMD could only be found in the group dosed with H-HEF concentration $(P<0.05)$. Nilestriol group demonstrated similar action on the BMD indicating the nilestriol was an effective positive control in the present study (Table 2).

\section{Serum $E_{2}$ was not altered by HEF}

As expected, the serum level of $E_{2}$ strikingly decreased in OVX group, indicating that the rats were estrogen deficient. Treatment with nilestriol slightly increased the serum level of $\mathrm{E}_{2}$, but the value was not significant compared to the OVX group. Treatment with various concentrations of HEF did not alter the serum level of $\mathrm{E}_{2}(P>0.05)$ (Fig. 3).

\section{Serum level of BGP was enhanced by HEF}

The serum level of BGP in OVX group was higher than that in sham-operated group though no significance was observed $(P>0.05)$. After treatment with $\mathrm{HEF}$, the serum level of BGP was increased. Moreover, high-dose HEF administration remarkably increased the serum level of BGP, compared with shamoperated and OVX groups $(P<0.05)$ (Fig. 4).

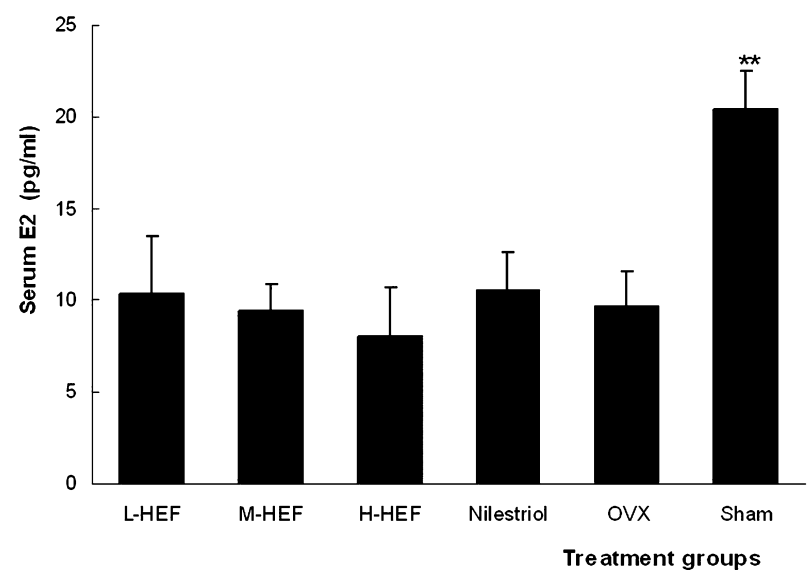

Fig. 3. Serum $E_{2}$ concentration in sham-operated rats (Sham); ovariectomized (OVX) rats treated with vehicle; OVX rats treated with L-HEF or M-HEF or H-HEF; OVX rats treated with nilestriol for 12 weeks. Data are means \pm SEM of nine rats. Different from OVX group: $* P<0.05$, $* * P<0.01$ by ANOVA. HEF, total flavonoids of Herba epimedii; OVX, ovariectomized; L-HEF, Low dose HEF; M-HEF, Middle dose HEF; H-HEF, High dose HEF.

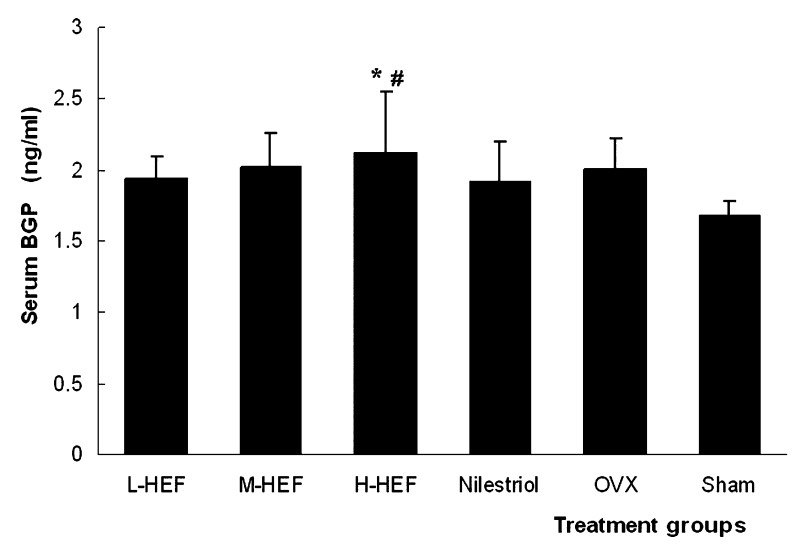

Fig. 4. Serum BGP concentration in sham-operated rats (Sham); ovariectomized (OVX) rats treated with vehicle; OVX rats treated with L-HEF or M-HEF or H-HEF; OVX rats treated with nilestriol for 12 weeks. Data are means \pm SEM of nine rats. Different from OVX group: ${ }^{*} P<0.05$; different from sham group: ${ }^{\#} P<0.05$ by ANOVA. HEF, total flavonoids of Herba epimedii; OVX, ovariectomized; L-HEF, Low dose HEF; MHEF, Middle dose HEF; H-HEF, High dose HEF.

Effect of icariin on BMP-2 expression in primary osteoblasts

After incubation with icariin, expression of BMP-2 was increased in a dose-dependent manner $(P<0.05)$. 
However, reduced BMP-2 expression was observed at higher icariin concentration (100 ng/ml) (Fig. 5).

\section{Relative quantitative expression analysis}

Real time amplification profiles for the target genes or ESTs fragments in bone tissues are shown in Fig. 6. After normalization to GAPDH, the values for fold changes were expressed relative to the calibrator with the lowest expression and displayed as relative expression. Genes that were not detected in any subject were excluded from statistical analysis. The expression level of Cbfal in sham-operated group was much higher than that in OVX group $(P<0.01)$. However, the administration of H-HEF and nilestriol recovered expression of Cbfa1. Furthermore, expression of $\mathrm{Cbfa} 1$
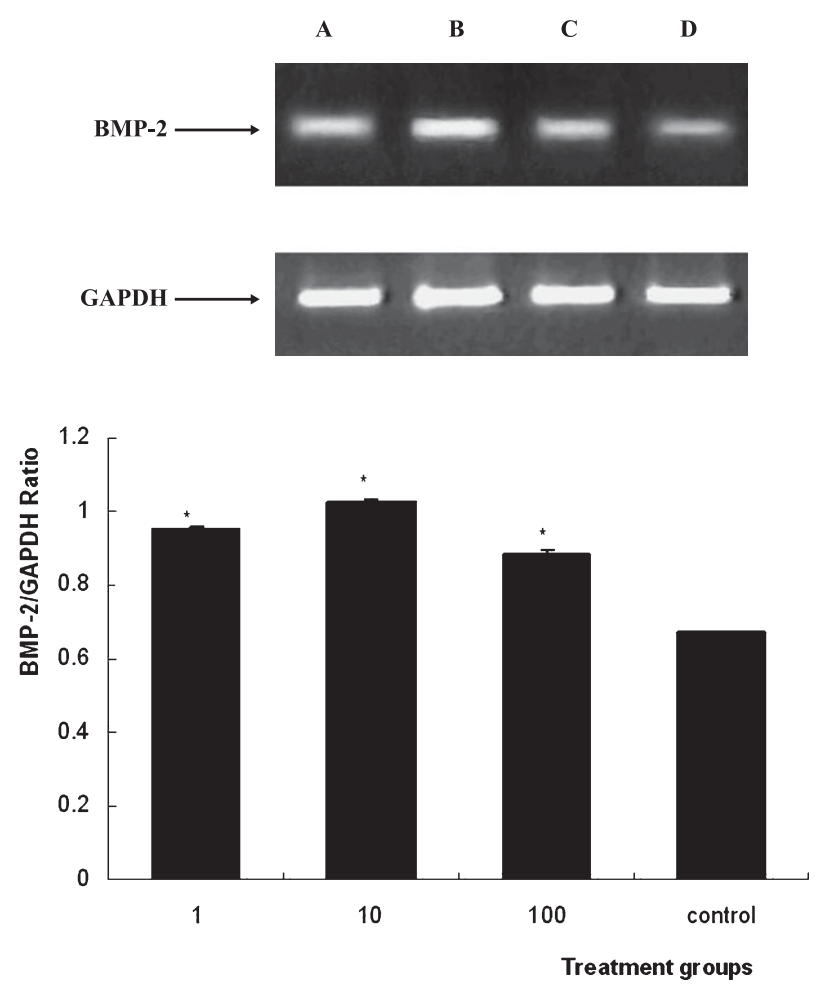

Fig. 5. Effect of icariin on BMP-2 mRNA expression in rat primary osteoblasts. Primary osteoblasts were treated with $1 \mathrm{ng} / \mathrm{ml}, 10 \mathrm{ng} / \mathrm{ml}$ and $100 \mathrm{ng} / \mathrm{ml}$ icariin or control for $48 \mathrm{~h}$. Total RNA was isolated and subjected to semi-quantitative RT-PCR analysis of BMP-2 mRNA expression under the conditions described in "Methods". Results were obtained from four independent experiments and expressed as means \pm SEM. Different from control group: ${ }^{*} P<0.05$ by ANOVA. (A: $1 \mathrm{ng} / \mathrm{ml}$; B: $10 \mathrm{ng} / \mathrm{ml}$; C: $100 \mathrm{ng} / \mathrm{ml}$; D: Control). in H-HEF group was even higher than that in shamoperated group $(P<0.01)$ (Fig. 7).

\section{GAPDH and Cbfa1}

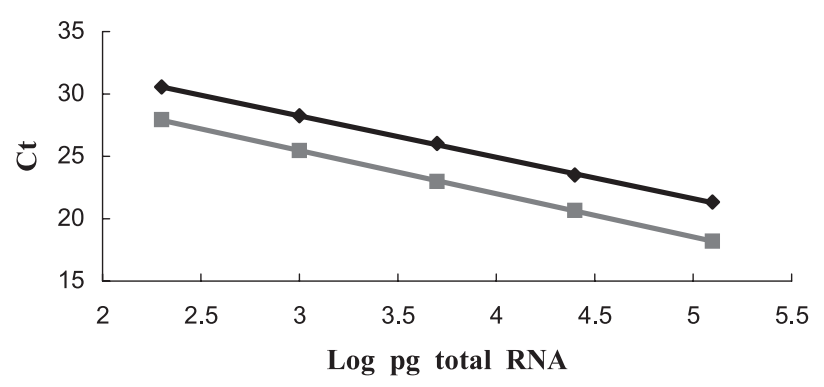

Fig. 6. Calibration curves constructed by measuring serial dilutions of rat bone tissue total RNA for relative quantification of target and reference genes expression. $\mathrm{Ct}$ values versus cDNA (reverse transcribed total RNA) concentration input were plotted to calculate the slope. The corresponding real time PCR efficiencies were calculated according to the equation: $E=10^{[-1 / \text { slope }]}$ (Rasmussen, 2001). GAPDH, glyceraldehyde. 3-phosphate dehydrogenase; $\mathrm{Ct}$, threshold cycle.

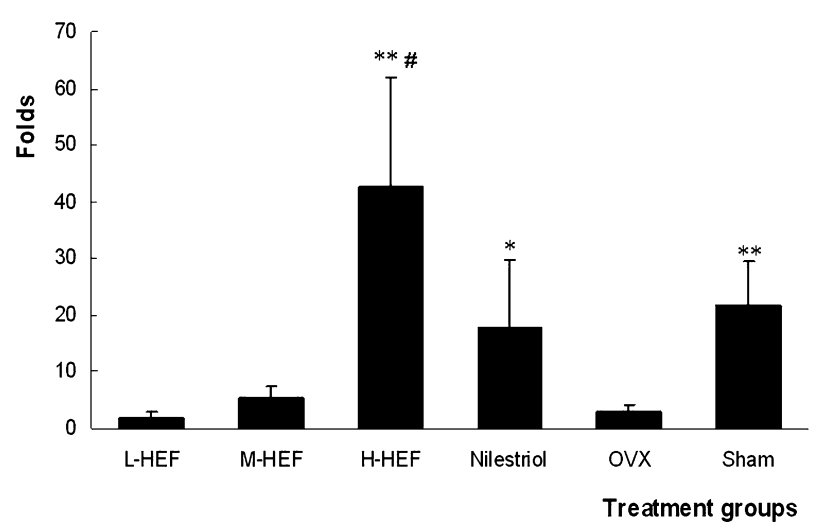

Fig. 7. Relative quantification of Cbfal mRNA expression in sham-operated rats (Sham); ovariectomized (OVX) rats treated with vehicle; OVX rats treated with L-HEF or M-HEF or H-HEF; OVX rats treated with nilestriol for 12 weeks. Data are means \pm SEM of nine rats. Different from OVX group: $* P<0.05, * * P<0.01$; different from sham group: ${ }^{\sharp} P<0.01$ by ANOVA. HEF, total flavonoids of Herba Epimedii; OVX, ovariectomized; L-HEF, Low dose HEF; M-HEF, Middle dose HEF; H-HEF, High dose HEF. 


\section{Discussion}

Estrogen has an important impact on bone. Loss of ovarian function may cause a $30 \%$ decrease of skeletal mass in women after menopause, due to their bone resorption increase and imbalance between the amounts of resorbed and formed bone at each remodeling site $[10,11]$. Bone loss in OVX animals is similar to that in postmenopausal women. Therefore, OVX rat represents an appropriate model to study postmenopausal osteoporosis.

Indeed, decreased level of serum $\mathrm{E}_{2}$ and $\mathrm{BMD}$, increased serum BGP, urine NTx (data not listed) and body weight observed in OVX rats collectively suggested our animal model of osteoporosis by ovariectomy was successful.

Besides, treatment with nilestriol increased the serum level of $E_{2}$, but the value was not significant from that in OVX group. As nilestriol derives from estriol $\left(\mathrm{E}_{3}\right)$, the above result might be relevant to conversion of $E_{3}$ to $E_{2}$.

We observed that the bone loss induced by ovariectomy was successfully prevented by the treatment with $\mathrm{HEF}$, but HEF failed to improve the level of serum $\mathrm{E}_{2}$ in OVX rats, indicating that HEF might contribute to its antiosteoporotic effect without increasing the level of serum $\mathrm{E}_{2}$. In addition, the present finding implies a possible involvement of a master regulatory gene(s) in this process.

Cbfa1 is a transcription factor, which is essential for osteoblast differentiation and bone formation. The expression of Cbfa1 mRNA in bone tissues was reduced by ovariectomy, which might be related to the lower level of serum $E_{2}$ in OVX rats [12-15]. Treatment with HEF prevented reduction of Cbfa1 mRNA expression from ovariectomy indicating that HEF may exert its action on bone metabolism by modulating Cbfa1. It seemed that this regulation on $\mathrm{Cbfa} 1$ was not relevant to the level of serum $E_{2}$ because the level of serum $E_{2}$ was not influenced by HEF. Our study demonstrated that icariin, the major constituent of HEF, could increase the expression of BMP-2 mRNA in primary osteoblasts. BMP-2 is a member of transforming growth factor- $\beta$ family. It appears to be an effective inducer for osteogenesis and upregulates the expression of Cbfa1 through Smads signal pathway [16]. Another study also showed that BMP-2 can enhance osteoblast differentiation by an increase in expression of $\mathrm{Cbfa} 1$ [17]. However, the pathway of regulation on Cbfal by HEF remains unknown and it needs further research.

BGP is a bone matrix protein secreted exclusively by differentiated osteoblasts and is believed to be one of the most reliable makers for bone formation. Earlier studies demonstrated that runt domain in Cbfal gene could bind to osteoblast-specific cis-acting element 2 (OSE2) in the promoter of the rat BGP gene, thereby Cbfa1 regulated the expression of BGP [18]. The expressions of these genes might be induced by $\mathrm{Cbfa} 1$, but a Cbfa1-specific antisense oligonucleotide could block Cbfal-induced bone anabolic activity $[6,19]$. Treatment with HEF increased the level of serum BGP in a dose-dependent manner, which was consistent with the regulation of HEF on Cbfal expression. It suggests that HEF exerts in vivo osteogenic effects via Cbfa1 transactivation, which then enhances expression of BGP. But an additional question of interest pertains to the reason(s) that expression of Cbfa1 was decreased in OVX group compared with sham-operated group, even though the level of serum BGP in OVX group was higher. Fujita et al. [20] found that ovariectomy could suppress expression of BGP, which was in accordance with the present finding. So the exact role of Cbfal on BGP expression in OVX animals is subject for further investigation.

In conclusion, our findings demonstrated that HEF had antiosteoporotic effects on ovariectomized rats. HEF could promote the mRNA expression of Cbfal, which might partly contribute to its antiosteoporotic effect.

\section{Acknowledgements}

We would like to thank Zhousheng Xiao, Bogeng Song and Hong Ao for their excellent technical assistance during this study. This study was supported by the National Natural Sciences Foundation of China (30070375). 


\section{References}

1. Xie F, Wu CF, Lai WP, Yang XJ, Cheung PY, Yao XS, Leung PC, Wong MS (2005) The osteoprotective effect of Herba epimedii (HEP) extract in vivo and in vitro. Evid Based Complement Alternat Med 2: 353-361.

2. Meng FH, Li YB, Xiong ZL, Jiang ZM, Li FM (2005) Osteoblastic proliferative activity of Epimedium brevicornum Maxim. Phytomedicine 12: 189-193.

3. Qin L, Zhang G, Hung WY, Shi Y, Leung K, Yeung HY, Leung P (2005) Phytoestrogen-rich herb formula "XLGB" prevents OVX-induced deterioration of musculoskeletal tissues at the hip in old rats. J Bone Miner Metab 23 Suppl: 55-61.

4. Ducy P, Zhang R, Geoffroy V, Ridall AL, Karsenty G (1997) Osf2/Cbfa1: a transcriptional activator of osteoblast differentiation. Cell 89: 747-754.

5. Komori T, Yagi H, Nomura S, Yamaguchi A, Sasaki K, Deguchi K, Shimizu Y, Bronson RT, Gao YH, Inada M, Sato M, Okamoto R, Kitamura Y, Yoshiki S, Kishimoto T (1997) Targeted disruption of Cbfal results in a complete lack of bone formation owing to maturational arrest of osteoblasts. Cell 89: 755-764.

6. Ducy P, Starbuck M, Priemel M, Shen J, Pinero G, Geoffroy V, Amling M, Karsenty G (1999) A Cbfa1dependent genetic pathway controls bone formation beyond embryonic development. Genes Dev 13: 10251036.

7. Xin ZC, Kim EK, Lin CS, Liu WJ, Tian L, Yuan YM, $\mathrm{Fu} \mathrm{J}$ (2003) Effects of icariin on cGMP-specific PDE5 and cAMP-specific PDE4 activities. Asian J Androl 5: $15-18$.

8. Rasmussen R (2001) Quantification on the LightCycler $^{\circledR}$ instrument. Methods and Applications. Springer Press, Heidelberg, pp. 21-34.

9. Bustin SA (2002) Quantification of mRNA using realtime reverse transcription PCR (RT-PCR): trends and problems. J Mol Endocrinol 29: 23-39.

10. Lin JT, Lane JM (2004) Osteoporosis: a review. Clin Orthop 126-134.

11. Jerome CP (2004) Hormonal therapies and osteoporosis. ILAR J 45: 170-178.

12. Zhou S, Zilberman Y, Wassermann K, Bain SD, Sadovsky Y, Gazit D (2001) Estrogen modulates estrogen receptor alpha and beta expression, osteogenic activity, and apoptosis in mesenchymal stem cells (MSCs) of osteoporotic mice. J Cell Biochem 81: 144 155.

13. Dang ZC, Van Bezooijen RL, Karperien M, Papapoulos SE, Lowik CW (2002) Exposure of KS483 cells to estrogen enhances osteogenesis and inhibits adipogenesis. J Bone Miner Res 17: 394-405.

14. Plant A, Samuels A, Perry MJ, Colley S, Gibson R, Tobias JH (2002) Estrogen-induced osteogenesis in mice is associated with the appearance of Cbfa1expressing bone marrow cells. J Cell Biochem 84: 285 294.

15. Lecka-Czernik B, Gubrij I, Moerman EJ, Kajkenova O, Lipschitz DA, Manolagas SC, Jilka RL (1999) Inhibition of Osf $2 / \mathrm{Cbfa} 1$ expression and terminal osteoblast differentiation by PPARgamma2. J Cell Biochem 74: 357-371.

16. Yamaguchi A, Komori T, Suda T (2000) Regulation of osteoblast differentiation mediated by bone morphogenetic proteins, hedgehogs, and Cbfa1. Endocr Rev 21: 393-411.

17. Gori F, Thomas T, Hicok KC, Spelsberg TC, Riggs BL (1999) Differentiation of human marrow stromal precursor cells: bone morphogenetic protein-2 increases OSF2/CBFA1, enhances osteoblast commitment, and inhibits late adipocyte maturation. J Bone Miner Res 14: 1522-1535.

18. Fujiwara M, Tagashira S, Harada H, Ogawa S, Katsumata T, Nakatsuka M, Komori T, Takada H (1999) Isolation and characterization of the distal promoter region of mouse Cbfa1. Biochim Biophys Acta 1446: 265-272.

19. Banerjee C, McCabe LR, Choi JY, Hiebert SW, Stein JL, Stein GS, Lian JB (1997) Runt homology domain proteins in osteoblast differentiation: AML3/CBFA1 is a major component of a bone-specific complex. $J$ Cell Biochem 66: 1-8.

20. Fujita T, Fukuyama R, Izumo N, Hirai T, Meguro T, Nakamuta H, Koida M (2001) Transactivation of core binding factor alphal as a basic mechanism to trigger parathyroid hormone-induced osteogenesis. Jpn J Pharmacol 86: 405-416. 